\title{
Metastatic Osseous Pain Control: Bone Ablation and Cementoplasty
}

\author{
Alexis Kelekis, MD, PhD, EBIR, FSIR ${ }^{1}$ Francois H. Cornelis, MD, PhD ${ }^{2}$ Sean Tutton, MD, FSIR ${ }^{3}$ \\ Dimitrios Filippiadis, PhD, MSc, EBIR ${ }^{1}$
}

1 Division of Diagnostic and Interventional Radiology, 2nd Department of
Radiology, University General Hospital "ATTIKON," Athens, Greece
2 Department of Radiology, Université Pierre et Marie Curie, Sorbonne
Université, Tenon Hospital, Paris, France
${ }^{3}$ Division of Vascular and Interventional Radiology, Department of
Radiology and Surgery, Medical College of Wisconsin, Milwaukee,
Wisconsin

Address for correspondence Alexis Kelekis, MD, PhD, EBIR, FSIR, Division of Diagnostic and Interventional Radiology, 2nd Department of Radiology, University General Hospital "ATTIKON," 1 Rimini street, 12462 Athens, Greece (e-mail: akelekis@med.uoa.gr).

Semin Intervent Radiol 2017;34:328-336

\begin{abstract}
Nociceptive and/or neuropathic pain can be present in all phases of cancer (early and metastatic) and are not adequately treated in 56 to $82.3 \%$ of patients. In these patients, radiotherapy achieves overall pain responses (complete and partial responses combined) up to 60 and $61 \%$. On the other hand, nowadays, ablation is included in clinical guidelines for bone metastases and the technique is governed by level I evidence. Depending on the location of the lesion in the peripheral skeleton, either the Mirels

\section{Keywords}

- ablation

- cementoplasty

- pain

- bone metastasis

- interventional radiology scoring or the Harrington (alternatively the Levy) grading system can be used for prophylactic fixation recommendation. As minimally invasive treatment options may be considered in patients with poor clinical status or limited life expectancy, the aim of this review is to detail the techniques proposed so far in the literature and to report the results in terms of safety and efficacy of ablation and cementoplasty (with or without fixation) for bone metastases. Percutaneous image-guided treatments appear as an interesting alternative for localized metastatic lesions of the peripheral skeleton.
\end{abstract}

Objectives: Upon completion of this article, the reader will be able to describe the basic concepts of ablation and peripheral skeleton augmentation and to identify the necessity for a tailored-based approach applying different techniques for different cases and locations.

Accreditation: This activity has been planned and implemented in accordance with the Essential Areas and Policies of the Accreditation Council for Continuing Medical Education (ACCME) through the joint providership of Tufts University School of Medicine (TUSM) and Thieme Medical Publishers, New York. TUSM is accredited by the ACCME to provide continuing medical education for physicians.

Credit: Tufts University School of Medicine designates this journal-based CME activity for a maximum of 1 AMA PRA Category 1 Credit $^{\mathrm{TM}}$. Physicians should claim only the credit commensurate with the extent of their participation in the activity.

Nociceptive and/or neuropathic pain can be present in all phases of cancer (early and metastatic) and are not adequately treated in 56 to $82.3 \%$ of patients. ${ }^{1,2}$ In these patients, radiotherapy achieves overall pain responses (complete and partial responses combined) up to 60 and $61 \%{ }^{3}$ International practice guidelines support the assertion that Single Fraction (SF) Radiotherapy (RTH) is the standard of care for pain relief due to bone metastasis; however, the unknown optimal single-fraction dose required to achieve pain relief is an important gap in knowledge in the interest of minimizing iatrogenic toxicity. ${ }^{3,4}$

In the market, there are different ablation techniques based on the energy type they use. These techniques include thermal ablation (laser, radiofrequency, microwave [MW] ablation, cryoablation, coblation), irreversible electroporation, and magnetic resonance (MR)-guided high-intensity focused ultrasound (HIFU). ${ }^{5-8}$ Percutaneous ablation in bone

Copyright (c) 2017 by Thieme Medical Publishers, Inc., 333 Seventh Avenue, New York, NY 10001, USA. Tel: +1(212) 584-4662.
Dol https://doi.org/ 10.1055/s-0037-1608747. ISSN 0739-9529.
Interventions in the Cancer Patient; Guest Editors, David Li, MD, PhD and David C. Madoff, MD 
metastatic disease can be proposed as curative treatment ( $<3-5$ lesions, $<3 \mathrm{~cm}$ in diameter) or as palliative treatment aiming at pain reduction, tumor decompression, and debulking. In weight-bearing areas, ablation results in osteonecrosis and bone weakening; thus, osseous augmentation is necessary for structural support.

Percutaneous cementoplasty with Poly(methyl methacrylate) (PMMA) injection can be either solely performed or in combination with instrumentation (screws, metallic or polyetheretherketone [PEEK] implants). To stratify the risk of pathologic fracture in patients with lesions in long bones, Mirels' scoring system is used, applying criteria of site, degree of pain, lesion characteristics, and size (each scored between 1 and 3). According to Mirels' scoring system, prophylactic fixation is recommended in cases of lesions in the peripheral skeleton long bones presenting a Mirels' score of $>8$. ${ }^{9}$ For acetabular bony defects, the Harrington or the Levy grading system is applied. ${ }^{10,11}$ While these numeric scoring systems were proposed to quantify the risk of sustaining a pathologic fracture through any metastatic lesion in a long bone or in the acetabulum, the decision to perform surgical fixation should also take into consideration the patient's performance status and disease progression. As the surgery of an impending fracture can have significant morbidity, minimally invasive treatment options may be considered in patients with poor clinical status or limited life expectancy. ${ }^{12}$

Percutaneous cementoplasty has proved to be highly effective for the palliation of pain from bone metastases. ${ }^{13,14}$ However, it was argued so far that it should be contraindicated for metastases that are located in long bones due to PMMA's biomechanical properties which render the material ideal for the spine where axial forces are applied but raise questions for locations in the peripheral skeleton where shear and torsional forces are applied. ${ }^{6,7,12-17}$ Several studies have now reported the promising outcomes of augmented osteoplasty and fixation performed concomitantly under imaging guidance. ${ }^{18-20}$

The purpose of this article is to describe the basic concepts of ablation and peripheral skeleton augmentation in metastatic bone disease. The role of protective techniques, biomechanics, and specific forces applied in different locations will be defined. Finally, the necessity for a tailored-based approach applying different techniques for different cases and locations will be addressed.

\section{Percutaneous Ablation}

\section{General Principles}

Percutaneous ablation of bone metastatic disease is performed under anesthesiology control (ranging from local anesthesia to sedation or general anesthesia which are more commonly preferred), extended sterility measures, and antibiotic prophylaxis. ${ }^{6-8,21}$ Imaging guidance is used for lesion targeting, and in cases of intact cortex, a trocar is hammered or drilled for initial approach. In such a case, the trocar should be withdrawn outside the expected ablation zone prior to energy application to avoid subsequent skin and soft-tissue burns, due to energy transfer through its shaft. Surrounding nerve and other sensitive structures should be protected whenever the ablation zone is expected to extend in a close proximity to them. Protective techniques include skin protection, temperature measurement, monitoring of nerve root function, and dissection of sensitive structures away from the ablation zone by means of balloons, gas, or fluid. ${ }^{6-8,22}$ A distance of $1 \mathrm{~cm}$ or more between a sensitive structure and the expected ablation zone is considered enough for safe ablation practice without the need of protective techniques. $^{6,7,22}$ Operator's experience, equipment availability, and tumor size and location are important factors for the choice of an ablation method. Ideally, the final result should be an ablation zone that encompasses the entire tumor to prevent a marginal recurrence. ${ }^{23}$

\section{Ablation Techniques}

Radiofrequency ablation is the most extensively studied and reported ablation technique. ${ }^{24-27}$ During monopolar electrode ablation, radiofrequency energy is applied through a closed circuit: the electrode acts as the circuit's cathode and the applied ground pads act as the anode with the energy being conducted from the generator to the electrode through the tissues to the grounding pads. The electrode's small sectional area results in very high energy flux while the large cross-sectional area of ground pads disperses and minimizes the energy flux. Bipolar radiofrequency electrodes do not need grounding pads; the flow of current is limited to the device tip, which includes both the anode and cathode (active and returning electrode) in the same probe. $^{23}$ During radiofrequency application, the ablation zone can vary widely according to the local tissue environment since it is highly affected by the tissue impedance, perfusion, and ventilation. ${ }^{28}$ Concerning musculoskeletal ablation, Rosenthal was the first who used radiofrequency energy for osteoid osteoma ablation in $1992 .^{29}$

Cryoablation is based on the Joule-Thomson theory and is a term used for the application of extreme cold aiming to the destruction of cells by means of both direct cellular and vascular injury; goal temperatures are between -20 and $-40^{\circ} \mathrm{C}$ where complete tissue necrosis occurs. ${ }^{30}$ Advantages of cryoablation include decreased intra- and postoperative pain, the clear visualization of the expanding ice ball during imaging which allows a more precise monitoring of the ablation zone, and the ability to use multiple cryoprobes simultaneously; however, all of these are possible at a higher cost (- Fig. 1). ${ }^{31,32}$ It is essential during cryoablation to achieve, within the ablation zone, a very low temperature at a fast rate; the most commonly used technique in bone cryoablation is a double 10-minute freeze technique with an intervening of 5 minutes passive thawing cycle. ${ }^{23}$ Active thawing is performed at the end of the session in order for the cryoprobes to be safely extracted.

During MW ablation, an oscillating MW field is created within which polar molecules like water continuously realign increasing kinetic energy and tissue temperature. ${ }^{33} \mathrm{MW}$ ablation as compared with radiofrequency results in faster and larger ablation zones of higher temperatures, as this energy radiates through all biological tissues, including those with high impedance such as bone. ${ }^{34}$ However, there are 


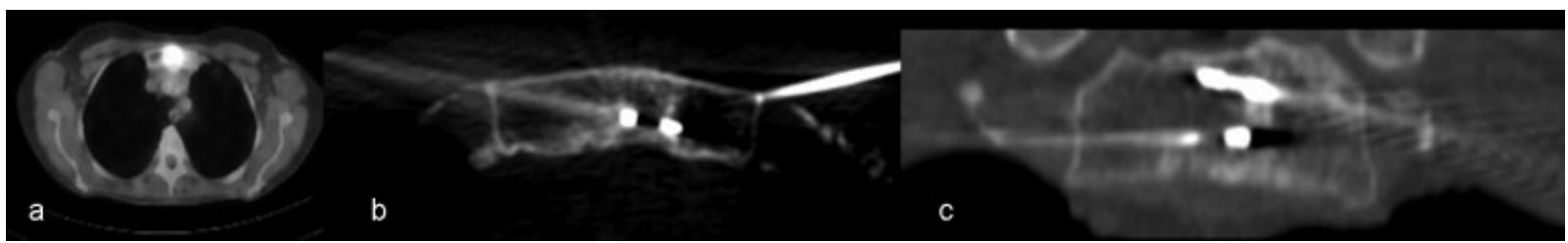

Fig. 1 Female patient with ovarian cancer and manubrium metastasis treated with cryoablation. (a) Positron emission tomography/computed tomography (PET/CT) scan illustrating an FDG avid sternal lesion. (b, c) CT axial and coronal reconstruction during the cryoablation session with two cryoprobes placed within the lesion.

fewer publications on MW ablation of bone lesions when compared with the radiofrequency or cryoablation literature. ${ }^{35,36}$ The variety in the design and wavelengths of the antenna and the power output of the generator are factors rendering a high learning curve necessary for the application of MW ablation. ${ }^{37}$

During laser ablation, a fiber transmits infrared light energy which results in cytotoxic temperature; however, the technique results in a small-sized ablation zone, although multiple laser fibers can be used. ${ }^{6,8}$ The most commonly used laser fiber is neodymium:yttrium-aluminum-garnet (Nd:YAG) diode laser fiber ranging from 800 to $1,100 \mathrm{~nm}$; at $2 \mathrm{~W}$ light energy applied for 6 to 10 minutes, a spherical ablation zone of $1.6 \mathrm{~cm}$ is produced. ${ }^{23,38}$

During HIFU, focused ultrasound energy is delivered at the target lesion resulting in focal elevated temperatures and coagulation necrosis; it is a noninvasive technique usually performed under MR guidance which apart from targeting provides real-time thermal monitoring as well. ${ }^{39}$

\section{Metastatic Bone Disease and Ablation}

The vast majority ( $\sim 80 \%$ ) of cancer patients with metastatic disease will develop bone metastases and will require therapy aiming in pain reduction and local tumor control. ${ }^{40}$ Indications for percutaneous ablation in metastatic bone disease are twofold: first, it is a therapeutic technique for patients with oligometastatic disease $(<3-5$ lesions, $<3 \mathrm{~cm}$ in diameter) and second, it is a palliative therapy for pain reduction and tumor decompression.

\section{Curative intent in oligometastatic bone disease:}

Five or fewer disease sites are generally considered to constitute oligometastatic disease and it can either be the result of the tumor's limited biologic capability to spread or it may present as a positive response to chemotherapy. ${ }^{41,42}$ In these patients, local tumor control of any known metastatic lesions by means of ablation either early in the oligometastatic disease course or as soon as chemotherapy downstaged the disease to oligometastatic one may result into a significant impact upon control of the systemic disease ending up in definite therapy. ${ }^{42}$ McMenomy et al have shown that percutaneous cryoablation is a safe and effective therapy for eradication of oligometastatic disease from multiple primary tumors to the musculoskeletal system with a single treatment session needed in $98 \%$ of cases to achieve a local control rate of $87 \%$, a major complication rate of $5 \%$, and a median postprocedural hospital stay of 1 day; authors report 91 and $84 \%$ for 1 - and 2-year overall survival rates, respectively, with a median overall survival of 47 months. ${ }^{42}$ Common prognostic factors influencing which patients with oligometastatic disease are more likely to benefit from percutaneous ablation include size and number of metastases, length of disease-free interval before onset of metastasis, adequacy of treatment of the primary tumor, and the presence of multiple metastatic sites. ${ }^{43,44}$

\section{Palliative therapy for pain reduction:}

Apart from percutaneous ablation, the therapeutic armamentarium for pain reduction in patients with bone metastatic disease includes analgesics, bisphosphonates, chemotherapy, hormonal therapy, and radiotherapy. Radiotherapy, although used frequently, is reported to provide partial pain relief in $70 \%$ of the treated patients while complete pain relief may be seen in up to one-third of the patients. ${ }^{45,46}$ The three-step analgesic ladder proposed by WHO seems to provide satisfactory pain management in the vast majority of cancer patients, but nearly one-third of them eventually will complain of refractory pain (which is defined as a nonresponsive type of pain). ${ }^{47}$ Additionally, despite its value, the administration of opioids is not without cost; dose and continuous use are factors directly affecting the risk of harm. ${ }^{48,49}$ Percutaneous ablation has become part of the treatment algorithm of painful metastatic bone disease with studies reporting significant efficacy upon pain reduction along with a safe profile. Similar reports can be found on MR-guided HIFU in the middle of the first paragraph, section 2 in Palliative therapy for pain reduction. ${ }^{26,27,32,35,39,50-58}$ The pathophysiology of pain reduction post-percutaneous ablation includes necrotizing tumor-periosteum interface, decompression of tumor volume, inhibition of osteoclast activity, and decrease in the nerve-stimulating cytokines released by the tumor., ${ }^{5,7}$ According to the most recent NCCN guidelines concerning adult cancer pain (v2, 2016), percutaneous ablation may be considered for metastatic bone pain palliation in cases without an oncologic emergency (e.g., pathologic fracture or epidural disease), when pharmacologic therapy is inadequate and radiation therapy is contraindicated or not desired by the patient. ${ }^{59,60}$

\section{Complications and Thermal Protective Techniques}

Complications of percutaneous ablation in metastatic bone disease generally present in the immediate postprocedural period and include thermal skin injuries, hemorrhage, nerve damage, inadvertent organ puncture, or collateral thermal injury. ${ }^{6-8,44}$ Skin injuries are usually treated with topical use 
of silver sulfadiazine or bacitracin; hemorrhage management may range from patient monitoring, volume resuscitation, blood transfusion, to embolization. ${ }^{44}$ Nerve injury may be temporary or permanent; a treatment with steroids (per os or infiltration) may enhance recovery in temporary nerve injury, while in permanent cases physical therapy or orthotics may be required. ${ }^{44,61}$

Preprocedural imaging with MRI will evaluate the proximity of neural structures to the expected ablation zone, while CT angiography will depict vulnerable vascular structures supplying the central neuroaxis. ${ }^{62}$ Gas, fluid, or balloons can be used for displacement of vital or sensitive structures (skin included) away from the ablation zone. Alternative skin protection technique includes the application of a sterile glove soaked in warm or frozen water depending on the ablation mode preferred (-Fig. 2). Temperature monitor may be performed by placing thermocouples at the margin of the desired ablation zone or near vital structures. ${ }^{62}$ Nervous structures can be further protected by neurophysiologic monitoring application by means of somatosensory or motor-evoked potentials. ${ }^{63}$

\section{Percutaneous Cementoplasty}

\section{General Principles}

Percutaneous cementoplasty of bone metastatic disease may involve injection of cement solely performed or in combination with metallic or PEEK screws and implants. The decision is based on lesion location and forces applied on this specific area. Although PMMA is an ideal material for the spine where axial forces are applied, the material's strength has poor perfor-



Fig. 2 Male patient with bronchogenic carcinoma and soft-tissue metastasis at the chest wall infiltrating the posterior rib at T11 and T12 level. Computed tomography axial scan illustrating the microwave antenna in the center of the metastatic lesion. Notice the presence of a sterile glove on the skin surface, filled with cold saline to avoid thermal injury. mance in the peripheral skeleton where rotational and shearing forces are applied and especially in weight-bearing locations. 6,7 Each of the variation techniques should be performed under imaging guidance, extensive local sterility (including prophylactic antibiosis), and anesthesiology control (wide range of depth depending on patient and location characteristics as well as operator's preference). ${ }^{6-8,21}$ Operator's experience, equipment availability, and lesion size and location are important factors for the choice of cementoplasty or fixation technique. In any case, the final result should be a construct extending up to normal bone for ideal anchorage and structural support. ${ }^{19}$

Depending on the location of the lesion, the Mirels score or the Harrington (or the Levy) grading systems can be applied in long bones and acetabulum, respectively. ${ }^{9-11}$ Furthermore, comorbidities and life expectancy should be evaluated as well. Technical characteristics concerning the lesion and the location govern the potential risk of pathologic fracture post cementoplasty or fixation; according to literature studies and reviews, the risk of pathologic fracture post cementoplasty seems to be higher for cortical involvement greater than $30 \mathrm{~mm}(n=7 / 11$ vs. $n=0 / 10 ; p=0.0005)$ and history of a previous fracture of the lesser trochanter $(n=3$ / 3 vs. $4 / 18 ; p=0.0009){ }^{12,64}$

\section{Bone Augmentation Techniques}

Cementoplasty using bone cement (PMMA) alone seems to be ineffective in femoral neck lesions and long bones involving the medulla, in general with risks of secondary fracture because of the multiple stresses applied in this location during weight bearing. ${ }^{65,66}$ As the tensile strength of cement is $35.3 \mathrm{MPa}$ in average, the shear strength is $42.2 \mathrm{MPa}$, the compressive strength is 93.0 MPa, the bending strength is $64.2 \mathrm{MPa}$, and the bending modulus is $2,552 \mathrm{MPa}$; cement is weak in tension, strong in compression, and has a low bending modulus of elasticity $(\sim 2 \times 103 \mathrm{MPa})$, lower than cortical bone $(\sim 20 \times 103 \mathrm{MPa}) .^{20,66}$ As opposed to vertebroplasty which has been proven to be an excellent technique for vertebral body fractures where axial-craniocaudal compression forces are mainly applied, it means that some intramedullary instrumentation is necessary for sufficient long-term stabilization of locations where rotational and shearing forces are applied. ${ }^{12}$ The addition of stainless steel or cobalt chrome alloy increases the shear strength, as modulus of elasticity for these two materials are $200 \times 103 \mathrm{MPa}$. Augmented osteoplasty may surpass the limitations of osteoplasty alone reported so far.

Percutaneous stabilization of impending pathological fracture of long bones using osteoplasty and fixation by screws or pins appears feasible even under conscious sedation (-Fig. 3). ${ }^{18}$ Tian et al compared the efficacy of percutaneous osteoplasty with and without interventional internal fixation by means of a needle in 40 patients. ${ }^{20}$ The patients were placed in a lateral position on an operating table. After local anesthesia, a 13-G bone puncture needle parallel to the axis of the femoral neck was inserted into the femur until the tip reached the bone cortex or the needle was completely inserted into the femur body. When fixation was performed, a modified trocar needle was implanted into the proximal femur through the bone puncture needle sheath. A maximal amount of PMMA as 


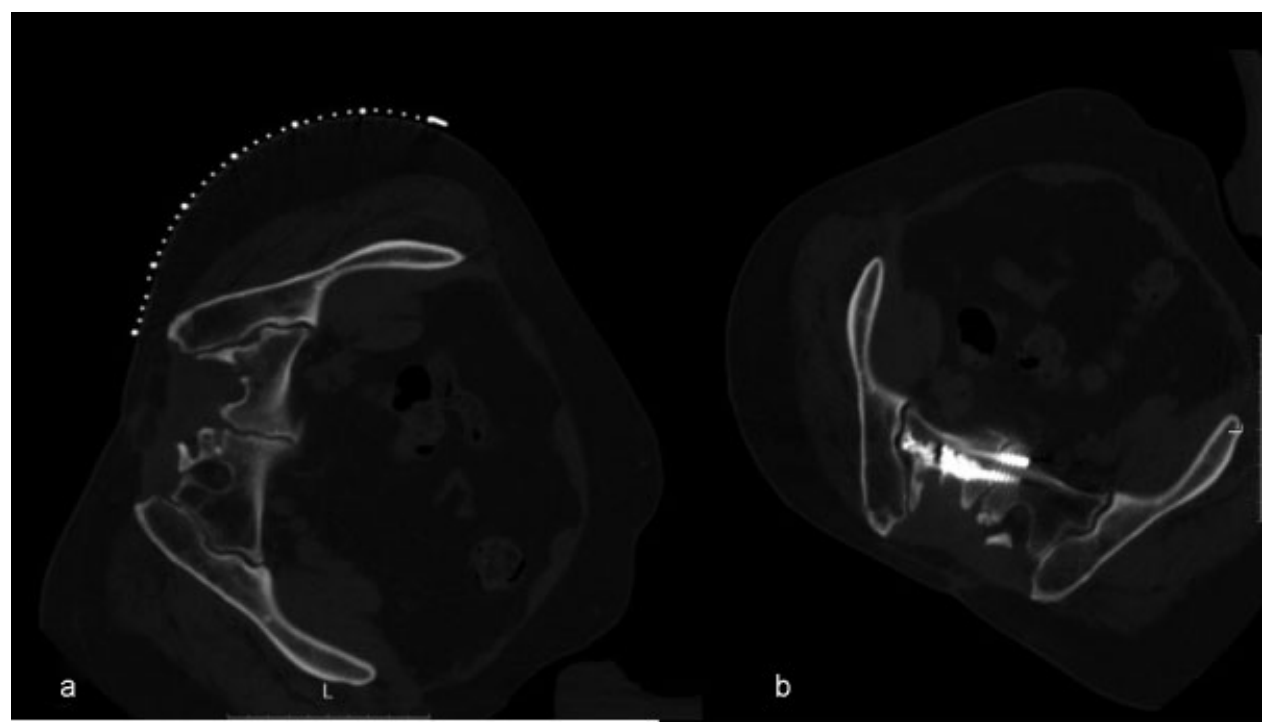

Fig. 3 Male patient with sacral sarcoma and secondary painful fracture postsurgery and radiotherapy. (a) Computed tomographic (CT) axial scan (patient is placed in lateral decubitus position) illustrating the wide fracture line at sacral midline and the lytic lesion at the right sacral wing. (b) CT axial scan illustrating cement at the lesion location and two cannulated screws percutaneously placed bridging the fracture line.

possible was injected into the femur through the bone puncture needle. Deschamps et al reported a $100 \%$ technical success for osteoplasty and fixation by screw in a study on 12 patients with metastasis of the proximal femur and mean Mirels' score of $9.8 \pm 1.2$ (range, $8-11$ ). ${ }^{18}$ The procedure was performed with 8 -mm cannulated screws after pin insertion parallel to the femoral neck under cone beam CT guidance. Specifically for the femoral neck, an inverted triangle configuration of screw placement was considered to be optimal for stabilization. The first guidewire was inserted along the inferior cortical of the femoral neck. The other two were placed against the upper cortical femoral neck-one posteriorly and the other anteriorly. Then PMMA was injected. The procedure was performed under general anesthesia $(n=6)$ or conscious sedation $(n=6)$. The mean duration was $110 \pm 43$ (range, 60-180) minutes. Additionally, in the literature, case reports and reviews report a highly efficacious and safe profile of percutaneous screws insertion either solely performed or in combination with cement injection. ${ }^{67,68}$

Another technique proposed by Kelekis et al, the REBAR concept, consists of performing percutaneous augmented peripheral osteoplasty with a metallic mesh of stainless steel micro-needles. ${ }^{19,69}$ This combination is easy to perform and seems to provide the necessary stability against the shearing forces applied in long bones during weight bearing; for optimal structural support, anchorage to healthy bone should be obtained. ${ }^{69,70}$ Coaxially a metallic mesh consisting of 25 to 50 medical grade stainless steel micro-needles (22 G, $2-6 \mathrm{~cm}$ in length) was inserted in 12 patients. A direct access to the lesion of interest was obtained by bone access needles. Specifically in the femoral bone, the access of the needle was introduced through the greater trochanter, following the natural lines of the Haversian canal system (-Fig. 4). PMMA for vertebroplasty was finally injected under fluoroscopic control.
In a prospective study published by Cornelis et al, 10 patients with Mirels' score 8 to 11 underwent Y-STRUT (Hyprevention, Pessac, France) implantation. ${ }^{71}$ This device was dedicatedly designed to enhance biomechanical structure of the femur and to prevent fracture ( - Fig. 5). ${ }^{72}$ It consists of two implants made of a radiotransparent PEEK polymer material. Under general anesthesia and $\mathrm{CBCT}$ guidance, the two implants composing the device were inserted along guidewires using a dedicated instrumentation ensuring the adequate connection in situ between the two components. The perforation of the implants allows controlling injection of the PMMA and fixation in 3D. The cement aims to increase the surface contact between the bone and the device and to anchor the device in the proximal femur. The mean duration of intervention was $97 \pm 28$ minutes (range, 60-155 minutes) and hospitalization was 2.3 days (range, 1-5 days). The consolidation of the femoral head by this implantable medical device was studied through biomechanical tests in vitro, on human femurs, to simulate falls on anatomical pieces. This study demonstrated the potential of Y-STRUT to improve the biomechanical performance of the proximal femur. ${ }^{72}$ The loadings until failure showed that the insertion of the implant increased significantly $(p=0.05)$ both fracture load $(+18 \%)$ and energy to fracture $(+32 \%)$ of the implanted femurs in comparison with the intraindividual controls. The instrumented femur resisted the implementation of the noninstrumented femur fracture load for 30 cycles and kept its performance at the end of the cyclic loading. This is consistent with previous biomechanical side-impact testing on pairs of femur using the same methodology. ${ }^{73}$

\section{Metastatic Bone Disease and Percutaneous Bone Augmentation}

Indications for percutaneous cementoplasty in metastatic bone disease are twofold: first, it is a palliative technique for cancer patients suffering from pathological fractures 


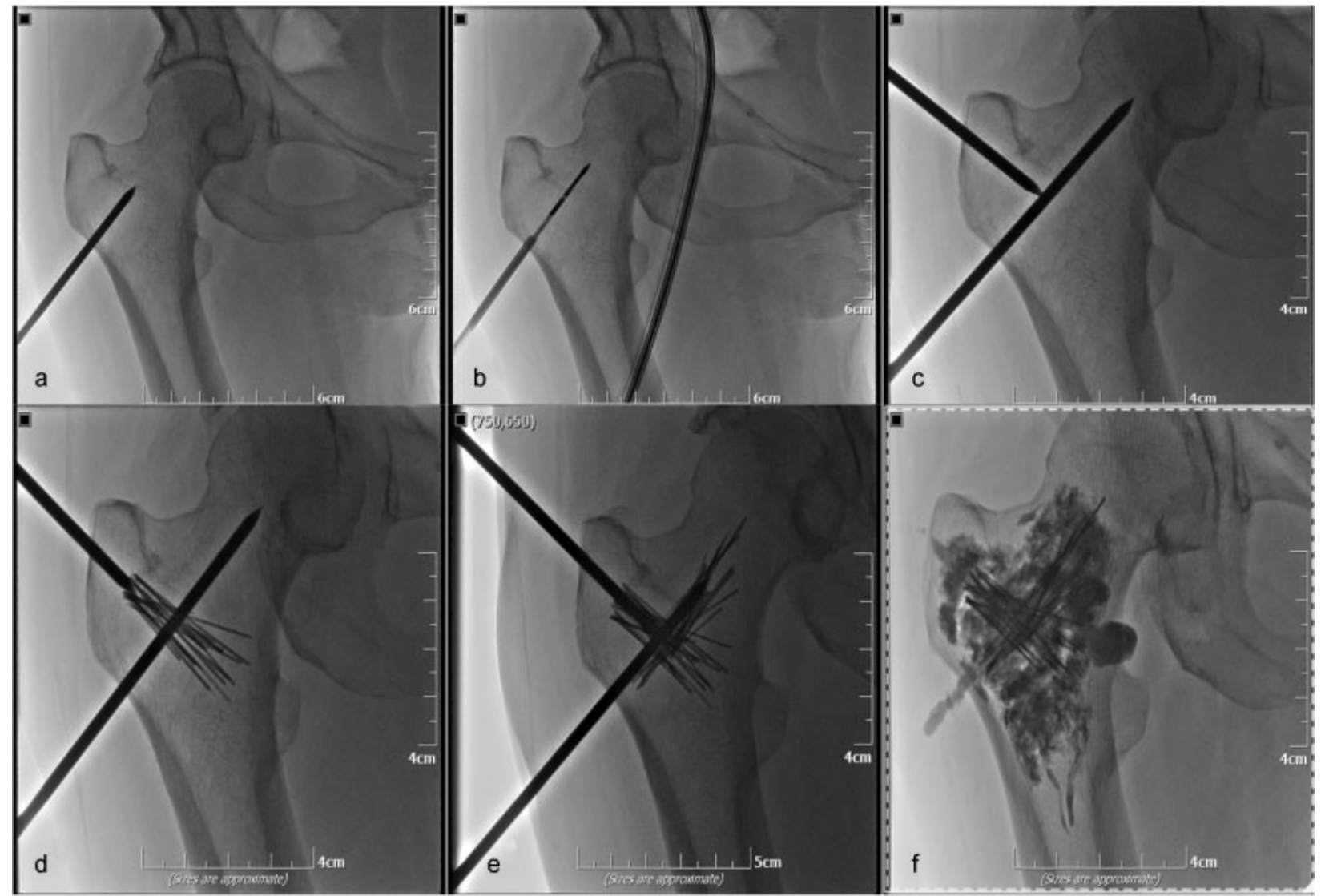

Fig. 4 Female patient with renal cell carcinoma and oligometastatic disease (two lesions, one in femoral bone and one in the scapula)-fluoroscopy anteroposterior views. (a) Bone access needle was inserted along the femoral neck. (b) Microwave antenna was coaxially inserted and ablation session was performed. (c) A second bone access needle was inserted with cranio-caudal direction. (d, e) Metallic micro-needles (22 G) were coaxially introduced through both the access needles to create a mesh (REBAR concept). (f) PMMA was injected covering the whole extent of the lesion and the metallic mesh and bridging the construct to normal bone.

and second, it is a preventive technique providing prophylactic consolidation for patients with impending pathological fractures due to osteolytic metastases.

\section{Palliation of pathological fracture:}

In pathologic fracture cases, ideally the cement should be injected within the fracture line and extend to normal bone for supportive anchorage. However, in real life, cement injection is governed by unpredictable diffusion tendency and second, in case of cement leakage to soft tissues, an incomplete filling of the fracture line might not promote the expected stability and thus keep the risk of delayed pathologic fracture. ${ }^{12,19,64}$ Furthermore, the already mentioned biomechanic properties of PMMA question stabilization of locations where rotational and shearing forces are applied. ${ }^{12}$ To overcome all these drawbacks, augmented osteoplasty techniques have emerged; these techniques include fixation by means of cannulated screws either solely placed or in combination with cement injection. To avoid screw loosening and migration, screws should be placed in resistant and, if possible, cortical bone in both sides and cement could be injected for optimum anchorage. ${ }^{70}$
The stabilization can be accompanied by ablation, depending on the nature of the fracture (necrotic, postradiotherapy, intralesional, etc.)

Until now, the tendency of percutaneous techniques was to treat undisplaced fractures, although nowadays there are accumulated reports showing that percutaneous realignment is feasible, followed by stabilization. ${ }^{68}$

2. Prophylactic consolidation for impending pathologic fractures due to osteolytic metastases:

In case of prophylactic consolidation for impeding pathologic fractures due to an osteolytic metastasis, fixation is done either by means of cannulated screws (solely placed or in combination with cement injection) or other augmented osteoplasty technique variations by means of nails, cementfilled catheters, Kirschner wires, PEEK polymers implants, or a metallic mesh of micro-needles in combination with PMMA injection. ${ }^{12,19,64,67,71,73-75}$ Prior to consolidation of osteolytic metastases, percutaneous ablation can be performed applying any kind of available energy including radiofrequency, MW, or cryoablation, depending on the algorithm of treatment used. ${ }^{76-79}$ 




Fig. 5 Preventive stabilization. Fluoroscopy anteroposterior view illustrating the Y-STRUT implant inside the femoral bone along with cement to increase the surface contact between the bone and the device and to anchor the device in the proximal femur.

\section{Conclusion}

Percutaneous treatments are increasingly recognized and used for metastatic disease in bone. Ablation can be proposed as curative treatment $(<3-5$ lesions, $<3 \mathrm{~cm}$ diameter) or as palliative treatment aiming in pain reduction, tumor decompression, and debulking. In case of weight-bearing locations, it results in osteonecrosis and bone weakening; thus, osseous augmentation is necessary for structural support.

Percutaneous bone augmentation techniques by means of cement are adequate where primarily compressive forces are involved. Cannulated screws nails, cement-filled catheters, Kirschner wires, PEEK polymer implants, or a metallic mesh of micro-needles in combination with PMMA injection can be proposed for treatment of pathologic fracture or prophylactic consolidation of impeding fracture, when shearing forces are prevalent. Which combinations (technique, lesion, location) are ideal still needs to be evaluated both in vitro and in vivo.

\section{References}

1 Coleman R, Body JJ, Aapro M, Hadji P, Herrstedt J; ESMO Guidelines Working Group. Bone health in cancer patients: ESMO Clinical Practice Guidelines. Ann Oncol 2014;25(03):124-137

2 Ripamonti CI, Santini D, Maranzano E, Berti M, Roila F; ESMO Guidelines Working Group. Management of cancer pain: ESMO Clinical Practice Guidelines. Ann Oncol 2012;23(07):139-154

3 Dennis K, Makhani L, Zeng L, Lam H, Chow E. Single fraction conventional external beam radiation therapy for bone metas- tases: a systematic review of randomised controlled trials. Radiother Oncol 2013;106(01):5-14

4 Chow E, DeAngelis C, Chen BE, et al. Effect of re-irradiation for painful bone metastases on urinary markers of osteoclast activity (NCIC CTG SC.20U). Radiother Oncol 2015;115(01):141-148

5 Rosenthal D, Callstrom MR. Critical review and state of the art in interventional oncology: benign and metastatic disease involving bone. Radiology 2012;262(03):765-780

6 Filippiadis DK, Tutton S, Kelekis A. Percutaneous bone lesion ablation. Radiol Med (Torino) 2014;119(07):462-469

7 Filippiadis DK, Tutton S, Mazioti A, Kelekis A. Percutaneous imageguided ablation of bone and soft tissue tumours: a review of available techniques and protective measures. Insights Imaging 2014;5(03):339-346

8 Gangi A, Tsoumakidou G, Buy X, Quoix E. Quality improvement guidelines for bone tumour management. Cardiovasc Intervent Radiol 2010;33(04):706-713

9 Mirels H. Metastatic disease in long bones. A proposed scoring system for diagnosing impending pathologic fractures. Clin Orthop Relat Res 1989;(249):256-264

10 Harrington KD. The management of acetabular insufficiency secondary to metastatic malignant disease. J Bone Joint Surg Am 1981; 63(04):653-664

11 Levy RN, Sherry HS, Siffert RS. Surgical management of metastatic disease of bone at the hip. Clin Orthop Relat Res 1982;(169):62-69

12 Deschamps F, Farouil G, Hakime A, et al. Cementoplasty of metastases of the proximal femur: is it a safe palliative option? J Vasc Interv Radiol 2012;23(10):1311-1316

13 Anselmetti GC, Manca A, Ortega C, Grignani G, Debernardi F, Regge D. Treatment of extraspinal painful bone metastases with percutaneous cementoplasty: a prospective study of 50 patients. Cardiovasc Intervent Radiol 2008;31(06):1165-1173

14 Kelekis A, Lovblad KO, Mehdizade A, et al. Pelvic osteoplasty in osteolytic metastases: technical approach under fluoroscopic guidance and early clinical results. J Vasc Interv Radiol 2005;16 (01):81-88

15 Dayer R, Peter R. Percutaneous cementoplasty complicating the treatment of a pathologic subtrochanteric fracture: a case report. Injury 2008;39(07):801-804

16 Chang SW, Murphy KP. Percutaneous CT-guided cementoplasty for stabilization of a femoral neck lesion. J Vasc Interv Radiol 2005;16(06):889-890

17 Basile A, Giuliano G, Scuderi V, et al. Cementoplasty in the management of painful extraspinal bone metastases: our experience. Radiol Med (Torino) 2008;113(07):1018-1028

18 Deschamps F, Farouil G, Hakime A, Teriitehau C, Barah A, de Baere T. Percutaneous stabilization of impending pathological fracture of the proximal femur. Cardiovasc Intervent Radiol 2012;35(06):1428-1432

19 Kelekis A, Filippiadis D, Anselmetti G, et al. Percutaneous augmented peripheral osteoplasty in long bones of oncologic patients for pain reduction and prevention of impeding pathologic fracture: the Rebar concept. Cardiovasc Intervent Radiol 2016;39(01):90-96

20 Tian Q-H, He C-J, Wu C-G, et al. Comparison of percutaneous cementoplasty with and without interventional internal fixation for impending malignant pathological fracture of the proximal femur. Cardiovasc Intervent Radiol 2016;39(01):81-89

21 Kelekis AD, Somon T, Yilmaz H, et al. Interventional spine procedures. Eur J Radiol 2005;55(03):362-383

22 Tsoumakidou G, Garnon J, Ramamurthy N, Buy X, Gangi A. Interest of electrostimulation of peripheral motor nerves during percutaneous thermal ablation. Cardiovasc Intervent Radiol 2013;36 (06):1624-1628

23 Motamedi K, Levine BD, Bukata SV, Genshaft S. Percutaneous image-guided musculoskeletal tumor treatments. AJR Am J Roentgenol 2016;207(03):517-525

24 Callstrom MR, Charboneau JW, Goetz MP, et al. Painful metastases involving bone: feasibility of percutaneous CT- and US-guided radio-frequency ablation. Radiology 2002;224(01):87-97 
25 Carrafiello G, Laganà D, Ianniello A, et al. Radiofrequency thermal ablation for pain control in patients with single painful bone metastasis from hepatocellular carcinoma. Eur J Radiol 2009;71 (02):363-368

26 Dupuy DE, Liu D, Hartfeil D, et al. Percutaneous radiofrequency ablation of painful osseous metastases: a multicenter American College of Radiology Imaging Network trial. Cancer 2010;116 (04):989-997

27 Goetz MP, Callstrom MR, Charboneau JW, et al. Percutaneous image-guided radiofrequency ablation of painful metastases involving bone: a multicenter study. J Clin Oncol 2004;22(02):300-306

28 Hong K, Georgiades CS. Radiofrequency ablation: mechanism of action and devices. In: Hong K, Georgiades CS, ed. Percutaneous Tumor Ablation: Strategies and Techniques. New York, NY: Thieme; 2011:1-14

29 Rosenthal DI, Alexander A, Rosenberg AE, Springfield D. Ablation of osteoid osteomas with a percutaneously placed electrode: a new procedure. Radiology 1992;183(01):29-33

30 Georgiades CS, Marx JK. Cryoablation: mechanism of action and devices. In: Hong K, Georgiades CS, ed. Percutaneous Tumor Ablation: Strategies and Techniques. New York, NY: Thieme; 2011:15-26

31 Littrup PJ, Bang HJ, Currier BP, et al. Soft-tissue cryoablation in diffuse locations: feasibility and intermediate term outcomes. J Vasc Interv Radiol 2013;24(12):1817-1825

32 Callstrom MR, Dupuy DE, Solomon SB, et al. Percutaneous imageguided cryoablation of painful metastases involving bone: multicenter trial. Cancer 2013;119(05):1033-1041

33 Lubner MG, Brace CL, Hinshaw JL, Lee FT Jr. Microwave tumor ablation: mechanism of action, clinical results, and devices. J Vasc Interv Radiol 2010;21(8, Suppl):S192-S203

34 Amabile C, Ahmed M, Solbiati L, et al. Microwave ablation of primary and secondary liver tumours: ex vivo, in vivo, and clinical characterisation. Int J Hyperthermia 2017;33(01):34-429

35 Pusceddu C, Sotgia B, Fele RM, Melis L. Treatment of bone metastases with microwave thermal ablation. J Vasc Interv Radiol 2013;24(02):229-233

36 Kastler A, Alnassan H, Aubry S, Kastler B. Microwave thermal ablation of spinal metastatic bone tumors. J Vasc Interv Radiol 2014;25(09):1470-1475

37 Hinshaw JL, Lubner MG, Ziemlewicz TJ, Lee FT Jr, Brace CL. Percutaneous tumor ablation tools: microwave, radiofrequency, or cryoablation-what should you use and why? Radiographics 2014;34(05):1344-1362

38 Gangi A, Tsoumakidou G, Buy X, Garnon J, Sabharwal T, Douarte R. Percutaneous bone treatment management. In: Mueller PR, Adam A, eds. Interventional Oncology; A Practical Guide for the Interventional Radiologist. New York, NY: Springer; 2012:169-183

39 Napoli A, Anzidei M, Marincola BC, et al. MR imaging-guided focused ultrasound for treatment of bone metastasis. Radiographics 2013;33(06):1555-1568

40 Nielsen OS, Munro AJ, Tannock IF. Bone metastases: pathophysiology and management policy. J Clin Oncol 1991;9(03):509-524

41 Hellman S, Weichselbaum RR. Oligometastases. J Clin Oncol 1995; 13(01):8-10

42 McMenomy BP, Kurup AN, Johnson GB, et al. Percutaneous cryoablation of musculoskeletal oligometastatic disease for complete remission. J Vasc Interv Radiol 2013;24(02):207-213

43 Weichselbaum RR, Hellman S. Oligometastases revisited. Nat Rev Clin Oncol 2011;8(06):378-382

44 Kurup AN, Callstrom MR. Ablation of musculoskeletal metastases: pain palliation, fracture risk reduction, and oligometastatic disease. Tech Vasc Interv Radiol 2013;16(04):253-261

45 Frassica DA. General principles of external beam radiation therapy for skeletal metastases. Clin Orthop Relat Res 2003;(415, Suppl): S158-S164

46 Lutz S, Chow E. A review of recently published radiotherapy treatment guidelines for bone metastases: contrasts or convergence? J Bone Oncol 2012;1(01):18-23
47 Vayne-Bossert P, Afsharimani B, Good P, Gray P, Hardy J. Interventional options for the management of refractory cancer pain-what is the evidence? Support Care Cancer 2016;24(03):1429-1438

48 Martin BC, Fan MY, Edlund MJ, Devries A, Braden JB, Sullivan MD. Long-term chronic opioid therapy discontinuation rates from the TROUP study. J Gen Intern Med 2011;26(12):1450-1457

49 Ballantyne JC, Kalso E, Stannard C. WHO analgesic ladder: a good concept gone astray. BMJ 2016;352:i20

50 Gangi A, Buy X. Percutaneous bone tumor management. Semin Intervent Radiol 2010;27(02):124-136

51 Mercadante S. Malignant bone pain: pathophysiology and treatment. Pain 1997;69(1-2):1-18

52 Callstrom MR, Atwell TD, Charboneau JW, et al. Painful metastases involving bone: percutaneous image-guided cryoablation-prospective trial interim analysis. Radiology 2006;241(02):572-580

53 Prologo JD, Passalacqua M, Patel I, Bohnert N, Corn DJ. Imageguided cryoablation for the treatment of painful musculoskeletal metastatic disease: a single-center experience. Skeletal Radiol 2014;43(11):1551-1559

54 Wallace AN, McWilliams SR, Connolly SE, et al. Percutaneous image-guided cryoablation of musculoskeletal metastases: pain palliation and local tumor control. J Vasc Interv Radiol 2016;27 (12):1788-1796

55 Kastler A, Alnassan H, Pereira PL, et al. Analgesic effects of microwave ablation of bone and soft tissue tumors under local anesthesia. Pain Med 2013;14(12):1873-1881

56 Kinczewski L. Microwave ablation for palliation of bone metastases. Clin J Oncol Nurs 2016;20(03):249-252

57 Napoli A, Anzidei M, Marincola BC, et al. Primary pain palliation and local tumor control in bone metastases treated with magnetic resonance-guided focused ultrasound. Invest Radiol 2013;48(06): 351-358

58 Yeo SY, Elevelt A, Donato K, et al. Bone metastasis treatment using magnetic resonance-guided high intensity focused ultrasound. Bone 2015;81:513-523

59 National Comprehensive Cancer Network. Adult Cancer Pain v. 2; 2016. Available at: https://www.nccn.org/professionals/physician_gls/f_guidelines.asp. Accessed November 21, 2016

60 Tomasian A, Wallace AN, Hillen TJ, Jennings JW. Percutaneous ablation in painful bone tumors. Semin Musculoskelet Radiol 2016;20(05):472-485

61 Nazario J, Hernandez J, Tam AL. Thermal ablation of painful bone metastases. Tech Vasc Interv Radiol 2011;14(03):150-159

62 Kurup AN, Schmit GD, Morris JM, et al. Avoiding complications in bone and soft tissue ablation. Cardiovasc Intervent Radiol 2017; 40(02):166-176

63 Kurup AN, Morris JM, Boon AJ, et al. Motor evoked potential monitoring during cryoablation of musculoskeletal tumors. J Vasc Interv Radiol 2014;25(11):1657-1664

64 Cazzato RL, Palussière J, Buy X, et al. Percutaneous long bone cementoplasty for palliation of malignant lesions of the limbs: a systematic review. Cardiovasc Intervent Radiol 2015;38(06): 1563-1572

65 Saha S, Pal S. Mechanical properties of bone cement: a review. J Biomed Mater Res 1984;18(04):435-462

66 Lewis G. Properties of acrylic bone cement: state of the art review. J Biomed Mater Res 1997;38(02):155-182

67 Deschamps F, de Baere T, Hakime A, et al. Percutaneous osteosynthesis in the pelvis in cancer patients. Eur Radiol 2016;26(06): 1631-1639

68 Garnon J, Koch G, Ramamurthy N, et al. Percutaneous CT and fluoroscopy-guided screw fixation of pathological fractures in the shoulder girdle: technical report of 3 cases. Cardiovasc Intervent Radiol 2016;39(09):1332-1338

69 Kelekis A, Filippiadis DK, Kelekis NL, Martin JB. Percutaneous augmented osteoplasty of the humeral bone using a combination of microneedles mesh and cement. J Vasc Interv Radiol 2015;26 (04):595-597 
70 Kelekis A, Martin JB, Anselmetti G, Filipiadis D. Regarding “percutaneous augmented peripheral osteoplasty in long bones of oncologic patients for pain reduction and prevention of impeding pathologic fracture: the Rebar concept": reply. Cardiovasc Intervent Radiol 2016;39(03):479-480

71 Cornelis FH, Tselikas L, Carteret T, et al. A novel implant for the prophylactic treatment of impending pathological fractures of the proximal femur: results from a prospective, first-in-man study. Cardiovasc Intervent Radiol 2017;40(07):1070-1076

72 Szpalski M, Gunzburg R, Aebi M, et al. A new approach to prevent contralateral hip fracture: Evaluation of the effectiveness of a fracture preventing implant. Clin Biomech (Bristol, Avon) 2015; 30(07):713-719

73 Beckmann J, Springorum R, Vettorazzi E, et al. Fracture prevention by femoroplasty-cement augmentation of the proximal femur. J Orthop Res 2011;29(11):1753-1758

74 Nakata K, Kawai N, Sato M, et al. Bone marrow nails created by percutaneous osteoplasty for long bone fracture: comparisons among acrylic cement alone, acrylic-cement-filled bare metallic stent, and acrylic-cement-filled covered metallic stent. Cardiovasc Intervent Radiol 2011;34(03):609-614

75 Nakata K, Kawai N, Sato M, et al. Percutaneous osteoplasty with a bone marrow nail for fractures of long bones: experimental study. J Vasc Interv Radiol 2010;21(09):1436-1441

76 Munk PL, Rashid F, Heran MK, et al. Combined cementoplasty and radiofrequency ablation in the treatment of painful neoplastic lesions of bone. J Vasc Interv Radiol 2009;20(07):903-911

77 Toyota N, Naito A, Kakizawa H, et al. Radiofrequency ablation therapy combined with cementoplasty for painful bone metastases: initial experience. Cardiovasc Intervent Radiol 2005;28(05):578-583

78 Proschek D, Kurth A, Proschek P, Vogl TJ, Mack MG. Prospective pilot-study of combined bipolar radiofrequency ablation and application of bone cement in bone metastases. Anticancer Res 2009;29(07):2787-2792

79 Pusceddu C, Sotgia B, Fele RM, Ballicu N, Melis L. Combined microwave ablation and cementoplasty in patients with painful bone metastases at high risk of fracture. Cardiovasc Intervent Radiol 2016;39(01):74-80 